\title{
Kernos
}

Revue internationale et pluridisciplinaire de religion grecque antique

29 | 2016

Varia

\section{Figures de dieux. Construire le divin en images}

\section{Hélène Collard}

\section{(2) OpenEdition \\ Journals}

Édition électronique

URL : http://journals.openedition.org/kernos/2455

DOI : 10.4000/kernos.2455

ISSN : 2034-7871

\section{Éditeur}

Centre international d'étude de la religion grecque antique

\section{Édition imprimée}

Date de publication : 1 octobre 2016

Pagination : 476-478

ISSN : 0776-3824

Référence électronique

Hélène Collard, «Figures de dieux. Construire le divin en images », Kernos [En ligne], 29 | 2016, mis en ligne le 01 octobre 2016, consulté le 17 novembre 2020. URL : http://journals.openedition.org/kernos/ 2455 ; DOI : https://doi.org/10.4000/kernos.2455

Ce document a été généré automatiquement le 17 novembre 2020.

Kernos 


\title{
Figures de dieux. Construire le divin en images
}

\author{
Hélène Collard
}

\section{RÉFÉRENCE}

Sylvia ESTIENNE, Valérie HUET, François LISSARRAGUE, Francis PRoSt (éd.), Figures de dieux. Construire le divin en images, Rennes, Presses universitaires de Rennes, 2014. 1 vol. $15,5 \times 24 \mathrm{~cm}, 380$ p. (Collection « Histoire »). ISBN : 978-2-7535-3522-0.

1 Le présent volume contient les actes d'un colloque qui s'est tenu à Paris en automne 2011, dans le cadre du groupe de recherche européen FIGVRA. Ce programme de recherche, coordonné par Nicole Belayche (EPHE - Paris) en partenariat avec diverses institutions et universités européennes (Rennes, Toulouse, Liège, Genève, Erfurt, Athènes), a donné lieu, entre 2008 et 2012, à quinze rencontres internationales et interdisciplinaires sur la vaste question de la représentation du divin dans les mondes grec et romain, dont celle-ci qui portait plus spécifiquement sur les représentations figurées. Si cet intérêt pour les images en contexte religieux n'est pas neuf en soi, ces dernières années, la manière et les moyens de les interroger ont été profondément renouvelés et réévalués, comme en témoignent plusieurs colloques et programmes collectifs récents ${ }^{1}$. Dans le sillage de cette féconde dynamique de réflexion, l'objectif de cette rencontre FIGVRA 14 était donc de poursuivre et d'affiner davantage encore les pistes récemment ouvertes en la matière.

2 L'ouvrage s'ouvre ainsi sur une brève introduction rédigée par les quatre éditeurs, qui y exposent les enjeux de l'entreprise en la resituant dans l'historiographie récente et dans la perspective générale du groupe de recherche. Viennent ensuite seize contributions assez disparates - dont sept sont consacrées au monde grec, sept au monde romain et deux à l'Égypte -, réparties en trois grandes parties thématiques, qui reflètent le programme du colloque. La première d'entre elles, consacrée à la mise en scène du divin, avait pour ambition d'étudier « les modalités pratiques de création des 
images divines et de leur activation » (p. 363). B. Holtzmann revient ainsi sur la très débattue question de la "statue de culte » en examinant les diverses statues d'Athéna sur l'Acropole d'Athènes et en essayant de comprendre ce qui les distinguait les unes des autres. D. Viviers s'intéresse lui aussi aux statues divines, et plus précisément à la fonction des statues transportées dans les processions grecques, en insistant sur les effets de théatralisation et de "mise en scène » de ces dispositifs rituels. En analysant les images du Genius Augusti à Rome, E. Rosso identifie deux formules iconographiques principales, qu'elle suggère de mettre en lien avec l'évolution chronologique du statut cultuel du Genius de l'empereur. D. Steuernagel s'attache quant à lui à la période hellénistique et aux offrandes faites à l'intérieur des temples en lien avec l'image divine - parures et vêtement, dépôts votifs, etc. -, qui attestent l'importance du contact et de la proximité avec celle-ci. Les deux dernières contributions concernent le volet romain : Fr. van Haeperen propose un réexamen du culte de Mater Magna à la lumière des images, principalement celles portées par les autels tauroboliques, bien connus mais encore peu envisagés pour leur iconographie, tandis que J.-Y. Marc et E. Rosso consacrent leur étude à la reconstitution et à l'interprétation d'une statue divine colossale retrouvée à Mandeure, dans laquelle on reconnaît généralement une copie du Mars Vltor augustéen.

3 Dans la deuxième partie, intitulée "Voir les dieux, penser le divin ", il s'agissait de s'interroger sur la fonction et la finalité de la figuration divine, mais aussi sur l'organisation intrinsèque de ces dispositifs visuels. D. Steiner revisite l'image des Gorgones représentées sur une amphore protoattique bien connue, pour suggérer que l'intention du peintre, par le recours à une iconographie originale, était de mettre en scène la rencontre avec le surnaturel et le divin. Y. Volokhine se penche sur un phénomène particulier, observable à l'extérieur des temples de l'Égypte gréco-romaine, qui consiste à enrichir et transformer les images planes des reliefs architecturaux en "statue » cultuelle, afin de rendre l'image divine accessible aux fidèles. V. Huet et St. Wyler, quant à elles, abordent la question des associations entre plusieurs divinités dans le culte domestique pompéien, que ce soit au sein d'un même laraire ou entre les différents laraires d'une même maison, et $\mathrm{C}$. Michel d'Annoville, à partir de la critique qu'en fait Arnobe, offre une réflexion sur la place des images divines en Afrique romaine aux $\mathrm{III}^{\mathrm{e}}$ et $\mathrm{IV}^{\mathrm{e}} \mathrm{s}$. de $\mathrm{n}$. ère. Cette partie se referme sur deux études ayant trait au monde grec: alors que Th. Morard reprend ici les grandes lignes de son ouvrage sur l'utilisation du double registre - les dieux en haut, les hommes en bas - dans la céramique apulienne ${ }^{2}$, J. Mylonopoulos revient sur la prétendue opposition entre simplicité et élaboration dans la conception des images divines, et montre que les artistes grecs ont en fait de tout temps fait appel aux deux procédés dans leur recherche de la meilleure stratégie pour visualiser le divin.

Enfin, la troisième et dernière partie aborde la question des effigies éphémères et de la valeur de ces images qui n'ont été créées ou utilisées que le temps d'un rituel. L. Coulon s'interroge sur le corpus des statuettes d'Osiris, fabriquées et remplacées annuellement à l'occasion des fêtes consacrées à ce dieu, et qui semblent ainsi aller à l'encontre des exigences égyptiennes quant à la durabilité des statues cultuelles. Fr. Frontisi-Ducroux reprend un dossier qu'elle connaît bien, celui du "masque de Dionysos", qu'elle propose, à la lumière de nouvelles données, de confronter à un autre dossier impliquant une image éphémère du dieu, celui du phallos. Viennent ensuite une étude de S. Estienne, visant à saisir les modalités de la construction du divin dans la temporalité spécifique des processions romaines, et un court article de P. Stewart, dans 
lequel il se penche, par la comparaison entre le monde romain et l'Inde contemporaine, sur l'usage des images votives éphémères, et en particulier l'offrande de pinakes faits de matériaux périssables.

5 Au terme de ce parcours, on se trouve face à un ensemble d'études très intéressantes, notamment pour les démonstrations méthodologiques et le renouvellement des interprétations qu'elles proposent. Toutefois, indépendamment de la qualité individuelle des différentes contributions et en dépit de l'agencement en trois parties thématiques, on pourra regretter que cet ouvrage collectif manque d'homogénéité. Certains articles ne répondent pas - ou pas suffisamment - à l'ambition du volume, qui était, rappelons-le, d' "apporter une contribution à la réflexion sur la représentation du divin en privilégiant l'image comme moyen d'investigation » (p. 361). Or ce qui est au centre de ce livre c'est davantage la perception visuelle - au sens large et dans ses diverses modalités - que la mise en image(s) du divin. Il est bien question d'images divines, en fait de statues divines majoritairement, mais pas de l'image au sens large, en tant que discours construit et mode de communication. On peut regretter que nombre d'auteurs n'aient pas davantage creusé la question du rôle de l'image dans le processus - antique - de construction du divin, ni de son apport, en tant qu'outil d'investigation, au questionnement - moderne - sur la représentation et la perception du divin ; en somme, on aurait aimé que soit davantage mise en lumière la spécificité du langage des images quand elles "présentifient l'invisible», pour reprendre les mots de J.-P. Vernant. On saluera néanmoins l'excellente contribution de Fr. Prost, qui, sous la forme de conclusions générales, permet de faire le point et de valoriser les acquis, ainsi que la grande qualité de l'illustration, dont 32 très belles planches en couleur. En résumé, il s'agit d'un livre utile, bien édité et bien documenté, qui vient renouveler des débats particuliers mais dont on aurait attendu davantage sur la thématique générale qu'il était censé affronter.

\section{NOTES}

1. Principalement: S. ESTIENNE et al. (éd.), Image et religion dans l'Antiquité gréco-romaine, Actes du colloque de Rome (11-13 décembre 2003), Naples, 2008 (Collection du Centre Jean Bérard, 28) ; et J. MYLONOPOUlos (éd.), Divine Images and Human Imaginations in Ancient Greece and Rome, Leiden/ Boston, 2010 (Religions in the Graeco-Roman World, 170).

2. .Th. MORARD, Horizontalité et verticalité. Le bandeau humain et le bandeau divin chez le Peintre de Darius, Mainz am Rhein, 2009. Voir le compte rendu qui en a été donné dans Kernos 24 (2011), p. 354-357. 


\section{AUTEURS}

HÉLÈNE COLLARD

(F.R.S.-FNRS - Université de Liège) 